built on the basis of a château en Espagne; the industries are already started and some practical conclusions are actually reached.

We were dealing, in our note, with the principles that underlie a large commercial undertaking in which the industries are run entirely for the benefit of consumptive working men, of whom 100 are already at work, and in connexion with which a considerable sum of money is passing through the hands of the business manager (a consumptive), the accounts being controlled and audited by an official auditor. This industrial colony is managed by and for consumptives, run on sound business lines and principles, in which consumptives in the colony village earn a full rate of wages for the number of hours they work, whilst others are being trained to follow in their footsteps. The turnover for these industries runs into five figures annually. In a booklet recently published we have anticipated the criticism contained in the first paragraph of Dr. Russell's letter :-

"Already the industries have a yearly turnover of many thousands of pounds. Serious work must be put in by all those employed ; life is again given that zest which is all the more real and stimulating because it is triumphing over unfavourable circumstances. We compete in the ordinary markets with our goods. There is no undercutting, but, as manufacturers of articles for the wholesale trade, we fall into line with those who produce goods in the ordinary commercial way. To sum up, we might say that a colony takes and makes use of all that is good in industrial life, whilst rejecting or altering much that is detrimental to the welfare of the consumptive worker." 1

Whether this is "visionary and extravagant," and whether the "commercial principle of supply and demand is wholly ignored," your readers will be able to judge.

As regards Dr. Russell's reference to pensions, we look upon them as "earned," and we maintain that in the case of consumptives they should be continued not as a gift or a dole, but as a right - as something awarded to a damaged man without which he is unable to continue on the level at which he was working and living before he entered the war. If Dr. Russell will come and look at the Papworth Colony (or make inquiries from some of his fellow-countrymen who have already visited the colony) he will find that it is possible to put into practice the plan concerning which he has such doubts; that it is neither visionary nor extravagant; and that it does not pauperise the worker. It is not a question of "if it were found possible"; the scheme is an accomplished fact, a striking success.

We are glad to know that such good results are being achieved at the Thompson Street Rooms, and we wish Dr. Russell all success in his efforts, for if proper provision cannot be made for consumptive wage-earners it is well that they should be educated, advised, and controlled; but whatever may be done with them in the workaday world they will always be tempted to overwork, and must remain more or less active centres of infection to those who work and live with them.

Finally, we cannot agree that taking a man to a sanatorium deprives him of his right arm, but we do realise that such a patient has indeed already been damaged, so far as capacity to engage in many industrial occupations is concerned, far more than by the loss of that right arm.

As to the last line of Dr. Russell's otherwise moderate letter, we should like to ask him whether it is more wicked to help a man to live a decent life and to keep his family with the aid of a pension than it is to leave that man in the surroundings in which he has contracted or laid the foundation of the disease, knowing the chances are that, although he may continue to work, he is all along fighting against long odds, and, whilst losing ground, must continue to be a centre of infection to his family and his fellows. We leave that to your readers to determine.-We are, Sir, yours faithfully,

Cambridge, July 24th, 1920 . P. C. VARRIER-JONES.

* * It seemed right to give those who were so strongly accused an immediate chance of reply.-ED. L.

${ }^{1}$ Industrial Colonies and Village Settlements for the Consumptive, p. 112. Cambridge University Press. London. 1920.

\section{SKIN AFFECTIONS AND GENERAL SYMPTOMATOLOGY.}

To the Editor of THE LANCET.

SIR,-Your short reference to a paper read by $\mathrm{Mr}$. Mollinson at the meeting of the British Medical Association at Cambridge, in which he says that septic conditions of the tonsils may be a source of various skin affections, such as psoriasis, touches the fringe of a large subject. Recently a child in good position, well cared for in all respects, was brought to me on account of psoriasis, which was rebellious to treatment. 1 found septic tonsils, and after these were removed the patient was cured.

But the pathology of psoriasis is practically unknown. Consequently the practitioner is debarred from frontal attack, and must ascertain in what way his patient, as a whole, departs from the normal. I believe it was Hebra who said that "psoriasis is a disease of the healthy." My own experience has taught me that if we can only investigate sufficiently, each victim of psoriasis will reveal some degree of pathologic deviation, which must be rectified before we can cure the disease. A large number of sufferers from psoriasis are chronically constipated. It is remarkable how many of these people are cured by the internal administration of petroleum, provided the petroleum cures the constipation. A Lane-Curtis belt is frequently a great help in bringing about this happy result.

Psoriasis is, of course, not the only affection of the skin that is profoundly influenced by a toxic state of the blood. In investigating any eruption, except those caused by known definite agents such as scabies and tinea, the first thing to do is to seek for any cause which may give rise to general systemic infection. The rôle played by carious teeth and pyorrhcea in increasing the vulnerability of the skin can scarcely be over-rated, and in dermatological practice it should be part of the routine to examine carefully the buccal cavity. In innumerable instances obstinate skin affections have been cured by the intelligent treatment of the patient when classic methods of fighting the disease have failed. I am, Sir, yours faithfully,

Birmingham, July 26th, 1920. ARTHUR LOXTON.

\section{THE INVESTIGATION OF RENAL EFFICJENCY.}

\section{To the Editor of THE LANCET.}

SIR,-While we agree with Dr. Harrington Sainsbury that the body does fortunately possess to some extent the power of compensating for disease of a particular organ or system, we are of opinion that careful study of the diseased organ offers the most fruitful prospect towards successful diagnosis, prognosis, and treatment. The utilisation of other resources of the body has long been recognised, and any advance in the knowledge of such mechanisms cannot fail to be of value. Unfortunately, these extra resources are often of minor importance; indeed, it is doubtful whether certain functions of the renal system are at all exereised by other organs.

We would point out, however, that such a test as the estimation of blood urea affords an index, not only of the efficiency of the kidney, but also of the general power of the body to eliminate urea.

With regard to Dr. E. W. Dewey's questions: (1) We have not tried urea in the treatment of cardiac oedema, but its diuretic properties might very possibly be of use in this connexion in certain cases. (2) A salt-free diet, or at any rate a very sparing use of salt, should be advantageous on theoretical grounds, and in practice we have several times found that the combination of urea and a practically salt-free diet gave good results, in difficult cases. (3) We have not seen any instance of uræmia being precipitated in interstitial nephritis by the administration of urea, nor do we think this contingency at all likely to arise. In the first place, it is very doubtful whether urea per se takes any part in the development of uræmia; and secondly, in an advanced case, in which the possibility of uræmia might have to be taken into consideration, the retention of urea in the 